\title{
AIDS-Indirect Research
}

National Cancer Institute

\section{Source}

National Cancer Institute. AIDS-Indirect Research. NCI Thesaurus. Code C19933.

Any studies (usually immunologic or virologic) that, although not directly concerned with AIDS, could reasonably be expected to contribute information useful in understanding or combatting AIDS. 